\title{
Effect of Laser Remelting on Friction-Wear Behaviors of Cold Sprayed Al Coatings in 3.5\% $\mathrm{NaCl}$ Solution
}

\author{
Zhang Jing and Kong Dejun * \\ School of Mechanical Engineering, Changzhou University, Changzhou 213164, China; \\ 16105527@smail.cczu.edu.cn \\ * Correspondence: djkong@cczu.edu.cn or kong-dejun@163.com; \\ Tel.: +86-0519-8116-9812; Fax: +86-0519-8116-9810
}

Received: 16 January 2018; Accepted: 9 February 2018; Published: 11 February 2018

\begin{abstract}
A cold sprayed Al coating on S355 structural steel was processed using a laser remelting (LR). The surface and cross-section morphologies, chemical compositions, and phases of as-obtained $\mathrm{Al}$ coating before and after LR were analyzed using a scanning electronic microscope (SEM), energy dispersive spectrometer (EDS), and X-ray diffractometer (XRD), respectively, and their hardness was measured using a micro-hardness tester. The friction-wear behaviors of Al coating before and after $\mathrm{LR}$ in $3.5 \% \mathrm{NaCl}$ solution were conducted to simulate the sand and gravel scouring on its surface in seawater, the effects of wear loads and speeds on the tribological properties of $\mathrm{Al}$ coating were analyzed, and the wear mechanisms under different wear loads and speeds were also discussed. The results show that the $\mathrm{Al}$ coating after $\mathrm{LR}$ is primarily composed of an $\mathrm{Al}$ phase and its hardness is $104.66 \mathrm{HV}$, increasing $54.70 \mathrm{HV}$ than the cold sprayed Al coating. The average coefficient of friction (COF) of cold sprayed Al coating at the wear load of $0.5,1.0$ and $1.5 \mathrm{~N}$ is 0.285 , 0.239 , and 0.435 , respectively, while that after LR is $0.243,0.227$, and 0.327 , respectively, decreased by $14.73 \%, 5.02 \%$ and $24.83 \%$ compared to the cold sprayed $\mathrm{Al}$ coating. The wear rate of cold sprayed $\mathrm{Al}$ coating at the wear load of $0.5,1.0$ and $1.5 \mathrm{~N}$ is $1.60 \times 10^{-4}, 2.36 \times 10^{-4}$, and $2.40 \times 10^{-4} \mathrm{~mm} / \mathrm{m} \cdot \mathrm{N}$, respectively, while that after LR is $1.59 \times 10^{-4}, 1.70 \times 10^{-4}$, and $1.94 \times 10^{-4} \mathrm{~mm}^{3} / \mathrm{m} \cdot \mathrm{N}$, respectively, decreased by $1 \%, 32 \%$, and $23 \%$, respectively, indicating that LR has high anti-friction performance. Under the wear load action of $1.0 \mathrm{~N}$, the average $\mathrm{COF}$ of laser remelted $\mathrm{Al}$ coating at the wear speeds of 300,400 and 500 times $/ \mathrm{min}$ is $0.294,0.279$, and 0.239 , respectively, and the corresponding wear rate is $1.06 \times 10^{-4}, 1.24 \times 10^{-4}$, and $1.70 \times 10^{-4} \mathrm{~mm}^{3} / \mathrm{m} \cdot \mathrm{N}$, respectively. The wear mechanism of cold sprayed Al coating is primarily corrosion wear at the loads of 0.5 and $1.0 \mathrm{~N}$, and that at the load of $1.5 \mathrm{~N}$ is abrasive wear and fatigue wear; while that after LR is abrasive wear and fatigue wear, with no corrosion wear, showing that LR improves its corrosion and wear resistance.
\end{abstract}

Keywords: cold spraying; $\mathrm{Al}$ coating; laser remelting (LR); friction and wear; corrosion wear; wear mechanism

\section{Introduction}

As a structural steel, S355 structural steel has the characteristics of high strength, plasticity and impact toughness etc. [1,2] and is mainly used in manufacturing of offshore platforms. When used in the marine environment for a long time, it is prone to corrosion and being worn by small sandstone; $\mathrm{Al}$ coating is generally used for protection. Cold spraying is a fabrication method of $\mathrm{Al}$ coating with plastic deformed Al powders impacted by high speed gas to combine with the substrate [3-8], because the cold sprayed $\mathrm{Al}$ coating presents a typical layered structure with micro-porosity, it is difficult to adapt to the harsh environment, which limits its scope of application and service life on offshore platforms $[9,10]$. In order to improve the properties of cold sprayed $\mathrm{Al}$ coating, the surface modification of $\mathrm{Al}$ coating is processed using a post-processing technology. Laser remelting (LR) 
is used to improve the hardness, wear resistance and corrosion resistance of $\mathrm{Al}$ coating, which has little effect on the surface roughness and the size of the coatings [11-13]. At present, LR has been used in post-processing to improve the performance of $\mathrm{Al}$ coating [14], and has achieved some results. Wang et al. fabricated a MCrAlY coating on Ti-Al alloy using plasma spraying: the lamellar micro-structure disappeared and the density increased and other defects disappeared after LR [15]; Astaritaa et al. used LR to modify the cold-sprayed Ti coating: the remelted zone (RZ), heat affected zone (HAZ) and base zone (BZ) were formed after LR [16]; Yao J et al. analyzed the beneficial effects of laser irradiation on the deposition process of cold-sprayed diamond and Ni60 composite coatings [17]. Almangour B et al. analyzed the scanning strategies for texture and anisotropy tailoring during selective laser melting of TiC/316L stainless steel nanocomposites and selective laser melting of TiC reinforced 316L stainless steel matrix nanocomposites: influencing the starting TiC particle size and volume content $[18,19]$. LR can effectively eliminate the layered structure and porosity of cold sprayed Al coating, and forms a uniform and compact structure, which is an effective way to improve the properties and expand the application range of cold sprayed Al coating [20-22]. In this study, a cold sprayed Al coating on S355 structural steel was processed using an LR. The friction-wear behaviors of $\mathrm{Al}$ coating were investigated to simulate the sand wear in seawater, which provided an experimental basis for the $\mathrm{Al}$ coating protection of S355 steel on offshore platforms.

\section{Experimental}

The substrate was European standard S355 structural steel with the chemical components (wt \%) C 0.17, Si 0.55, Mn 0.94, P 0.035, Cr 0.065, S 0.035, Ni 0.065, Mo 0.30 and Zr 0.15; the rest was Fe. The spraying process was as follows: mechanical polishing $\rightarrow$ chemical washing to remove oil $\rightarrow$ rust removal $\rightarrow$ rinsing and drying $\rightarrow$ cold sprayed Al coating $\rightarrow$ cooling $\rightarrow$ cleaning surface. The cold sprayed powder was pure $\mathrm{Al}$ particles with diameters $20-45 \mu \mathrm{m}$. The cold spraying test was conducted on Kinetiks 4000-type cold spraying equipment, and spraying parameters were as follows: pressure of $3.5 \mathrm{MPa}$, temperature of $400{ }^{\circ} \mathrm{C}$, the distance between spraying gun and sample was $40 \mathrm{~mm}$, gun speed of $200 \mathrm{~mm} / \mathrm{s}$, powder feeding of $1 \mathrm{~L} / \mathrm{min}$. After the cold spraying test, the obtained Al coating was sealed using a DIAMANT Dichtol WFT (1532) type sealing agent. The cold sprayed Al coating was remelted using a 2000W all-solid fiber coupling transmission laser spraying system; the technological parameters of LR are shown in Table 1. After the LR test, the surface and cross-section morphologies and chemical elements of $\mathrm{Al}$ coating were analyzed using a JSM-6360LA type SEM (NEC Electronics Corporation, Tokyo, Japan) and its configured EDS (NEC Electronics Corporation, Tokyo, Japan), respectively, and its phases were analyzed using a D/max2500 PC type XRD (Rigaku Corporation, Tokyo, Japan). The hardness of Al coating before and after LR was measured using an HMV-2T (Hardness Micro Vickers-2 Transformation) type Vickers micro-hardness tester (Shimadzu Enterprise Management (China) Co., Ltd., Shanghai, China).

Table 1. Technological parameters of cold sprayed Al coatings.

\begin{tabular}{cc}
\hline Item & Value \\
\hline Spray distance $/ \mathrm{mm}$ & 250 \\
Spot diameter $/ \mathrm{mm}$ & 5 \\
laser power $/ \mathrm{W}$ & 800 \\
Speed of argon gas $/ \mathrm{L} / \mathrm{min}$ & 8 \\
\hline
\end{tabular}

Before the friction-wear test, the samples were immersed in $3.5 \% \mathrm{NaCl}$ solution for $120 \mathrm{~min}$. The friction-wear test was carried out on a CFT-I type reciprocating friction-wear tester (Lanzhou Zhongke Kaihua Science and Technology Development Co. Ltd., Lanzhou, China), with a measurement accuracy of COF of $0.2 \%$ FS (full scale), a depth measurement range of $\pm 0.5 \mathrm{~mm}$, and accuracy of $0.1 \mu \mathrm{m}$. The $\mathrm{Al}$ coating was immersed in $3.5 \% \mathrm{NaCl}$ solution to investigate the effects of wear loads and wear speeds on the friction-wear behaviors of $\mathrm{Al}$ coating before and after LR, the friction-pair 
was a $\mathrm{Si}_{3} \mathrm{~N}_{4}$ ceramic ball with a diameter of $3.5 \mathrm{~mm}$, a wear distance of $5 \mathrm{~mm}$, a test time of $2 \mathrm{~h}$, a respective load of $0.5,1.0$, and $1.5 \mathrm{~N}$, and rotation speed of 500 times $/ \mathrm{min}$. After the above wear test, the optimized wear load was selected to compare the friction-wear behaviors at rotation speeds of 300, 400, and 500 times/min. The morphologies, chemical element distributions and phases of worn tracks were analyzed using a SEM, EDS, and XRD, respectively, and the wear profiles of worn tracks were measured using a VHX-700FC type super-depth three-dimensional microscopic system (Keyence Corporation, Osaka, Japan).

\section{Analysis and Discussion of Results}

\subsection{Characterization of Al Coatings}

\subsubsection{Morphologies of Al Coating Surfaces and Cross Sections}

The surface and cross-section morphology of cold sprayed Al coating before and after LR is shown in Figure 1a,b. The cold sprayed Al particles appeared as an obvious deformation when impacting on the substrate at high speed, which were distributed on the substrate as flat strips, and they were mechanically embedded with the substrate $[23,24]$. The Al particles were closely combined, and there was a clear interface between the particles, with no obvious porosity on the Al coating surface. The morphology of laser-remelted Al coating remained intact; its micro-structure was changed due to the laser thermal effect. After LR, the flat stripe and mosaic structure disappeared, the Al particles were fine and uniform, and the Al coating was almost completely compact. The porosity and inclusions were reduced greatly, and the remelted layer was obtained without cracks, porosity and other defects.

Figure 1c,d shows the highly-magnified morphology of cold sprayed Al coating surface before and after LR. The Al particles on the Al coating surface before LR were not tamped by the subsequent particles, the spherical powders remained intact, and the Al particles were obviously found on the Al coating surface. Compared with the cold sprayed Al coating, the profiles of $\mathrm{Al}$ particles were gradually desalinated after LR, which was due to the appearance of melted chip-shaped products in the LR process, which indicated that a little amount of dissolution at the edge of Al particles; however, the overall shape of Al particles changed little.

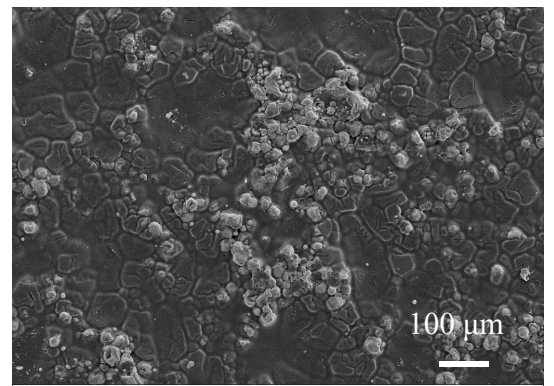

(a)

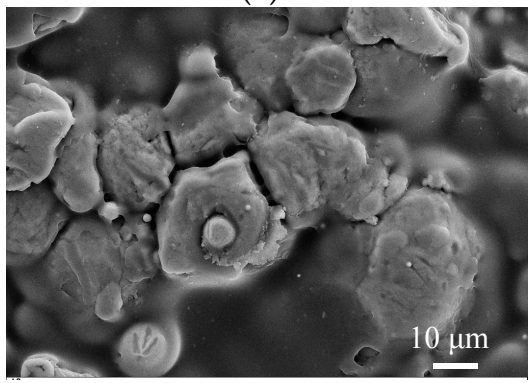

(c)

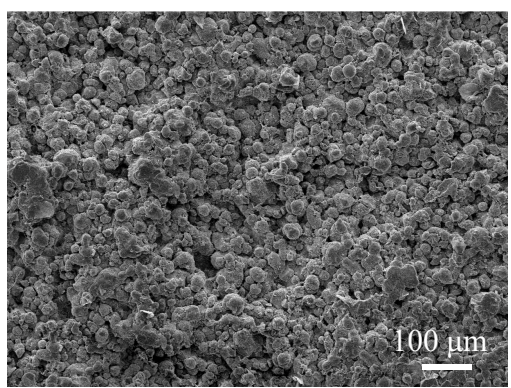

(b)

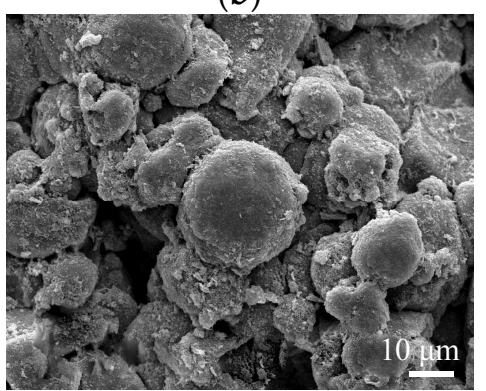

(d)

Figure 1. Cont. 


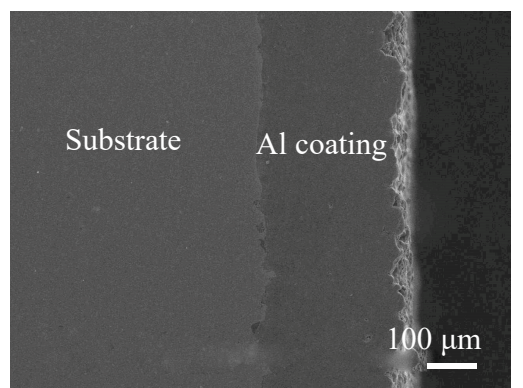

(e)

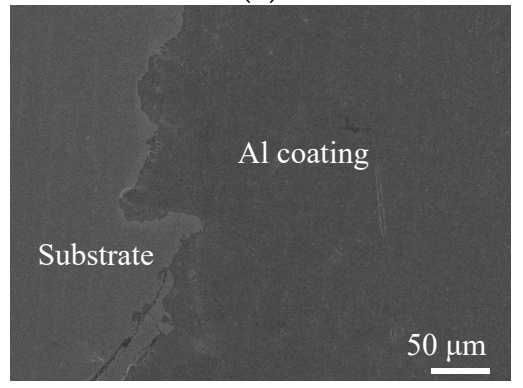

(g)

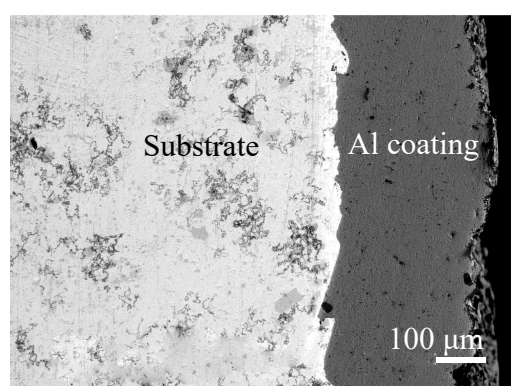

(f)

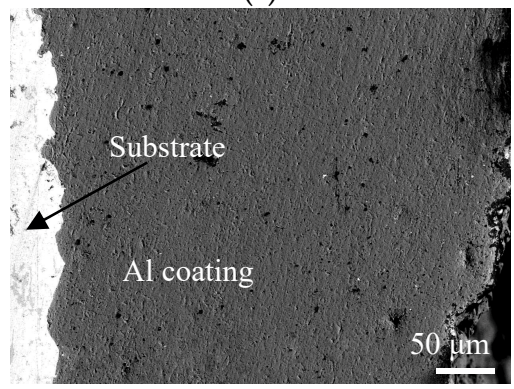

(h)

Figure 1. Surface and cross section morphologies of cold sprayed $\mathrm{Al}$ coating before and after laser remelting (LR). (a) Low-magnified surface morphology before LR; (b) Low-magnified surface morphology after LR; (c) High-magnified surface morphology before LR; (d) High-magnified surface morphology after LR; (e) Low-magnified cross-section morphology before LR; (f) Low-magnified cross-section morphology before LR; (g) High-magnified cross section morphology before LR; (h) High-magnified cross section morphology after LR.

Figure 1e,f shows the low-magnified cross-section morphology of cold sprayed Al coating before and after LR. Before LR, the Al coating was mechanically bonded with the substrate and the separation line of $\mathrm{Al}$ coating-substrate was obviously coherent, with no obvious defects. After LR, the cross-section of $\mathrm{Al}$ coating was smoother, the loose structure, fine porosity and micro-cracks were gradually eliminated with the laser powers increasing, and the grains of Al coating were refined. The porosity was unevenly distributed on the cross-section of Al coating, and its density was high.

Figure 1g,h shows the highly-magnified morphology of Al coating cross-section before and after LR. It can be seen that there were isolated porosity and cracks on the cross-section of $\mathrm{Al}$ coating before LR: due to the impact of the high speed in the cold spraying process, the Al particles with the un-melted state produced plastic deformation during the stacking process, and the grain boundaries remained among them. After LR, the Al coating was heated and cooled down very quickly during the LR process, which improved the micro-structure and eliminated the grain boundary between the $\mathrm{Al}$ particles. The porosity was accumulated near the substrate, this was because the cooling rate of $\mathrm{Al}$ coating near the coating surface was greater than that of $\mathrm{Al}$ coating near the substrate during the LR process, the inner gas was not discharged in time, and the porosity was formed near the substrate.

\subsubsection{XRD Analysis}

Figure 2 shows the XRD spectra of S355 steel and cold sprayed Al coating before and after LR. The phase of S355 steel was Fe, while that of cold sprayed Al coating was Al: no oxides were detected. After LR, the Al coating phase was the same with that before LR and the Al coating maintained the original phase and showed no phase transition; the Al particles were not oxidized after LR. This reason was shown as follows: (a) the Al powder phase stably existed due to low temperature during the cold spraying process; (b) although the bonding method of Al coating was changed from mechanical bonding to metallurgical bonding, no new phase was precipitated in the rapid cooling 
process, the original micro-structure of Al was inherited. Therefore, there was no phase transformation during the LR process.

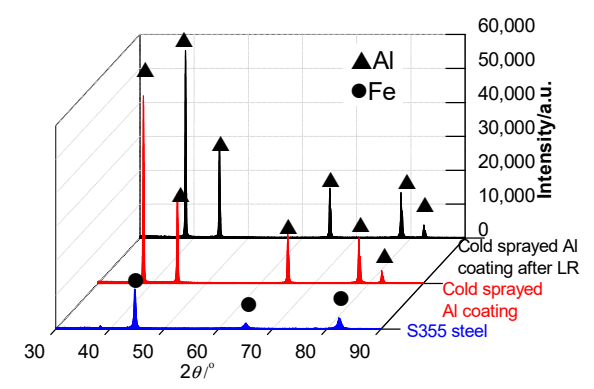

Figure 2. XRD analysis of cold sprayed Al coatings before and after LR.

\subsubsection{Hardness Analysis}

The surface hardness of cold sprayed Al coating before and after laser remelting is shown in Table 2. The average hardness of Al coating before LR was $49.96 \mathrm{HV}$, while that of Al coating after LR was 104.66 HV: an increase of $109 \%$ compared to before LR, which was related to the working hardening and thermal action during the LR test. In addition, the porosity of laser remelted $\mathrm{Al}$ coating was greatly reduced to almost completely compaction, which caused hardness of Al coating increase.

Table 2. Hardness of cold sprayed Al coating before and after LR.

\begin{tabular}{clllllc}
\hline Status & \multicolumn{4}{c}{ Value/HV } & & Average Value/HV \\
\hline Before LR & 47.2 & 49.3 & 52.3 & 47.7 & 53.3 & 49.96 \\
After LR & 101.4 & 104.6 & 100.5 & 106.2 & 110.6 & 104.66 \\
\hline
\end{tabular}

\subsection{COFs and Wear Profiles}

\subsubsection{Effect of Load on Friction-Wear}

Figure 3a shows the COFs of cold sprayed $\mathrm{Al}$ coating in $3.5 \% \mathrm{NaCl}$ solution at the loads of $0.5,1.0$ and $1.5 \mathrm{~N}$ (wear speed of 500 times/min). The COFs at the loads of $0.5,1.0$ and $1.5 \mathrm{~N}$ increased with the wear time increasing, which was related to the principle of cold sprayed Al coating. Under high-speed impact, the Al particles were deposited with severe plastic deformation: the first deposited particles were subjected to the impact of subsequent particles to form a micro-forging combination, which caused the bonding inside the Al coating to become stronger. According to the cold spraying mechanism, the density of cold sprayed Al coating increased gradually from the $\mathrm{Al}$ coating surface to the substrate. When the Al coating surface was peeled off, the ceramic ball gradually contacted with the higher hardness of Al coating, which caused the COF increase.

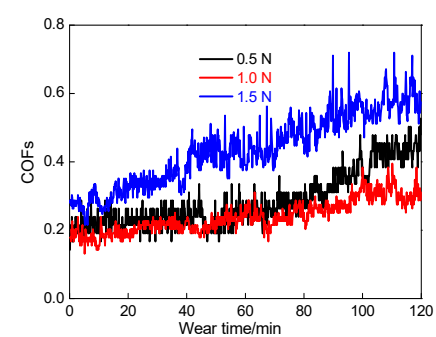

(a)

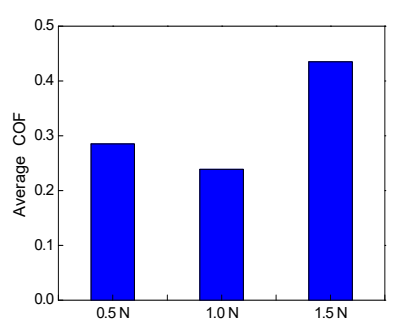

(b)

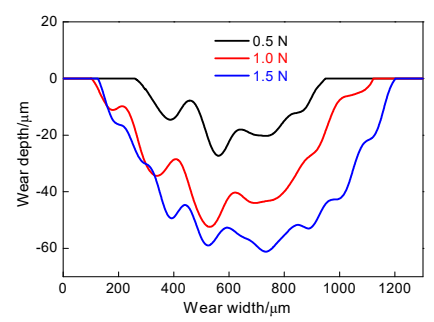

(c)

Figure 3. Coefficients of friction (COFs) vs. wear time and wear profiles of cold sprayed $\mathrm{Al}$ coatings before LR. (a) COFs vs. wear time; (b) Average COFs; (c) Wear profiles. 
The average COF of $\mathrm{Al}$ coating at the loads of $0.5,1$ and $1.5 \mathrm{~N}$ was $0.285,0.239$, and 0.435, respectively, and the standard deviation for $\mathrm{COF}$ of cold sprayed $\mathrm{Al}$ coating was $8.05 \times 10^{-2}$, $4.69 \times 10^{-2}$ and $10.49 \times 10^{-2}$, respectively; among them, the average COF and standard deviation for $\mathrm{COF}$ at the load of $1 \mathrm{~N}$ were the smallest, showing the better friction performance, as shown in Figure $3 \mathrm{~b}$. The friction pair at the load of $0.5 \mathrm{~N}$ moved on the shallow $\mathrm{Al}$ coating surface: the pits and peaks on the Al coating surface hindered the sliding of the ceramic ball. The Al coating surface was fluffy, which led to higher COFs. The friction layer at the load of $1 \mathrm{~N}$ was smooth in the Al coating depth. Because of actual contact stresses increasing, the $\mathrm{Al}$ coating was easily plowed and the pit was smooth, so the COFs were kept lower and the curve was stable. The Al coating surface at the load of $1.5 \mathrm{~N}$ was hardened due to plastic deformation, the friction pairs easily was stuck and decreased the shearing resistance [25-27], which led to large COFs.

The wear profile of $\mathrm{Al}$ coating in $\mathrm{NaCl}$ solution under different loads is shown in Figure 3c. The wear rate was calculated by the following equation:

$$
W=\frac{V}{S \times P}
$$

where $V$ was the wear losses of the coating; $S$ was the sliding distance; and $P$ was the normal load applied.

The wear rates of $\mathrm{Al}$ coatings at the loads of $0.5,1.0$ and $1.5 \mathrm{~N}$ were $1.60 \times 10^{-4}, 2.36 \times 10^{-4}$, and $2.40 \times 10^{-4} \mathrm{~mm}^{3} / \mathrm{m} \cdot \mathrm{N}$, respectively. The wear rates increased with the wear loads increasing, which was due to the shearing and compressive stress at the large wear loads was bonded among the Al particles, which increased with the wear loads increasing, and the falling probability of $\mathrm{Al}$ particles increased gradually. The fell particles were used as abrasive particles to wear the $\mathrm{Al}$ coating, which reduced the wear resistance and increased the wear rate.

The laser-remelted $\mathrm{Al}$ coating had regional characteristics because the laser beam spot was scanned at the certain speed on the $\mathrm{Al}$ coating: its surface was first heated and then the heating was transferred from the surface through the heat conduction into the inner coating, which caused an uneven distribution of temperature in the molten pool and produced the uneven mass-transfer in the molten pool. On the central region of the laser beam near the substrate, the pool temperature was very high, while the substrate temperature was relatively low due to the temperature gradient; the temperature-distribution and solidification rate were different on the regions of molten pool, which led to different micro-structures on the different regions of the molten layer $[28,29]$. The friction-wear properties of surface layer of $0 \sim 70 \mu \mathrm{m}$ on the cold sprayed Al coating after LR were mainly investigated, which is considered the surface layer as the remelted layer of $\mathrm{Al}$ coating.

Figure 4a shows the COFs of laser-remelted Al coating at the wear loads of $0.5,1.0$ and $1.5 \mathrm{~N}$ in $3.5 \% \mathrm{NaCl}$ solution (friction rate of 500 times $/ \mathrm{min}$ ), respectively. It can be seen that the COFs of laser-remelted $\mathrm{Al}$ coating fluctuated up and down in a certain range without a large overall upward or downward trend: this was because the Al coating after LR was affected by many factors, such as self-diffusion and gravity. Compared with the $\mathrm{Al}$ coating before LR, the structure after LR was very compact and uniform, the hardness was generally improved, and the hardness gradient on worn track disappeared, so the COFs fluctuated in a fixed range. The brittleness of worn track on the Al coating surface increased after LR. Because of the large shearing force and the fact that the bonding of the $\mathrm{Al}$ coating was unstable, some $\mathrm{Al}$ particles was flaked from the $\mathrm{Al}$ coating, and the peeled $\mathrm{Al}$ particles became new abrasive particles to participate in the wear test on the worn track. Due to the instability of new $\mathrm{Al}$ particles, which were easily dispersed into the $\mathrm{NaCl}$ solution during the wear test, the $\mathrm{COFs}$ were made to fluctuate up and down.

As shown in Figure $4 b$, the average COFs of cold sprayed Al coating after LR were $0.243,0.227$ and 0.327 , and the standard deviation for COF of cold sprayed Al coating was $2.66 \times 10^{-2}, 2.25 \times 10^{-2}$ and $3.63 \times 10^{-2}$, respectively; compared to that before LR, these values were generally lower, which was due to the increasing of $\mathrm{Al}$ coating hardness after LR. The depth of micro-convex or abrasive particles 
pressed into the $\mathrm{Al}$ coating surface decreased and the friction resistance reduced, which caused the coefficient decrease.

After LR, the profiles of worn tracks are shown in Figure 4c. The wear rates of $\mathrm{Al}$ coatings at the wear loads of $0.5,1.0$ and $1.5 \mathrm{~N}$ were $1.59 \times 10^{-4}, 1.70 \times 10^{-4}$ and $1.94 \times 10^{-4} \mathrm{~mm} / \mathrm{m} \cdot \mathrm{N}$, respectively, indicating that the wear depth increased with the wear loads increasing. Compared with the Al coating before $\mathrm{LR}$, the worn tracks of $\mathrm{Al}$ coating were smoother after $\mathrm{LR}$, which was due to the dense and high hardness of $\mathrm{Al}$ coating after $\mathrm{LR}$, the finer and smoother abrasive particles were flake, the worn track was a typical smooth pit shape.

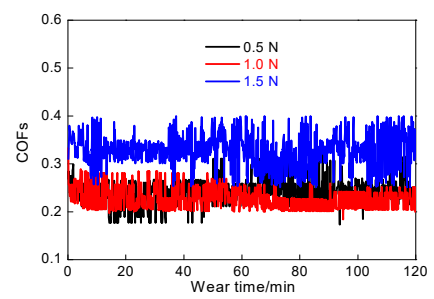

(a)

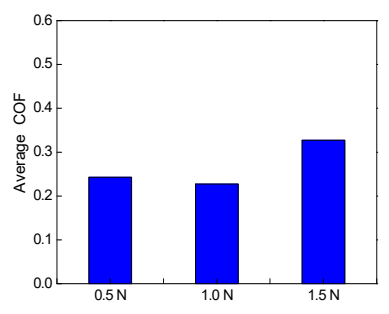

(b)

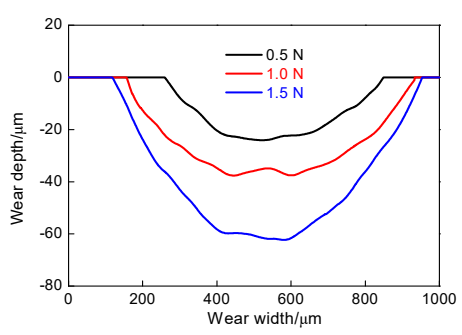

(c)

Figure 4. COFs vs. wear time and wear profiles of cold sprayed Al coatings after LR. (a) COFs vs. wear time; (b) Average COFs; (c) Wear profiles.

\subsubsection{Effect of Wear Speed on Friction-Wear}

It can be seen from the above that the average $\mathrm{COF}$ of laser-remelted $\mathrm{Al}$ coating at the load of $1.0 \mathrm{~N}$ was the smallest, indicating that the $\mathrm{Al}$ coating had better friction performance at the load. The friction-wear performance of cold sprayed $\mathrm{Al}$ coating in $3.5 \% \mathrm{NaCl}$ solution was analyzed by setting the load at $1.0 \mathrm{~N}$; meanwhile, changing the speed of friction pair. Figure $5 \mathrm{a}$ shows the COFs vs. different wear speeds. Figure $5 \mathrm{~b}$ shows the average $\mathrm{COFs}$ of $\mathrm{Al}$ coating at the different wear speeds. The average COFs at the wear speeds of 300, 400 and 500 times/min were 0.294, 0.279 and, 0.239, and the standard deviation for COF of cold sprayed Al coating was $1.62 \times 10^{-2}, 2.20 \times 10^{-2}$ and $2.25 \times 10^{-2}$, respectively. The above-average COFs were less than 0.3 at the wear speeds of 300,400 and 500 times/min, indicating that the Al coating had better friction performance after LR. The COFs became smaller with the wear speed increasing, and the variation of COFs tended to be more stable during the friction test, this was because when the wear speed was small, the surface temperature of friction pair in $\mathrm{NaCl}$ solution was lower, and the ceramic ball was easily cut and extruded the $\mathrm{Al}$ coating, so the wear amount was relatively low. However, the plastic deformation resistance of the friction pair was large: the plastic deformation resistance between the friction surfaces was mainly due to the interaction between the small convex peaks of contact surfaces between the friction surfaces, so the COFs were large when the friction resistance between the friction surfaces was larger. With the friction speeds increasing, the COFs of friction pair were reduced effectively under the synergistic action of water lubrication and the friction contact area increased.

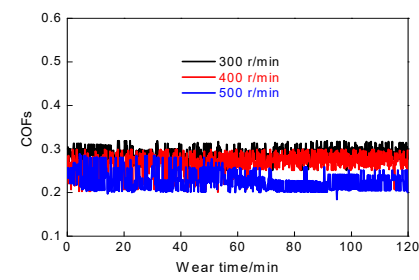

(a)

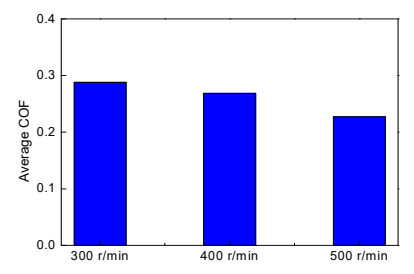

(b)

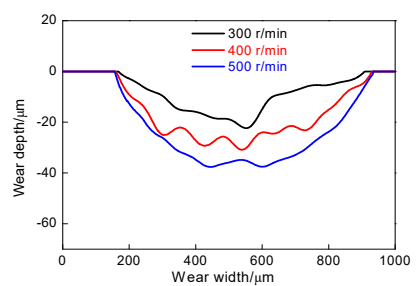

(c)

Figure 5. COFs vs. wear time and wear profiles of cold sprayed Al coatings after LR at different wear speeds. (a) COFs vs. wear time; (b) Average COFs; (c) Wear profiles. 
From Figure 5c, it can be seen that the wear pits were smooth and few irregular pits appeared. The maximum depth of corresponding pits at the wear speeds of 300, 400 and 500 times/min was 23, 30 and $37 \mu \mathrm{m}$, respectively. The corresponding wear rate was $1.06 \times 10^{-4}, 1.24 \times 10^{-4}$, and $1.70 \times 10^{-4} \mathrm{~mm}^{3} / \mathrm{m} \cdot \mathrm{N}$, indicating that the wear rates increased with the wear speeds increasing, the wear of fine abrasive particles on the worn track were accelerated to increase the wear amount.

\subsection{Plane Scanning Analysis of Worn Tracks}

The plane scanned position of a worn track at the wear speed of 300 times/min (wear load of $1.0 \mathrm{~N}$ ) is shown in Figure 6a. The plane scanning result is shown in Figure $6 \mathrm{~b}$, and the mass fractions of chemical elements (mass, \%) were C 65.14, $\mathrm{O} 23.90, \mathrm{Na} 0.07, \mathrm{Al} 10.45$, and $\mathrm{Cl}$ 0.35; the corresponding atomic fractions (at, \%) were $\mathrm{Al} 27.86, \mathrm{C} 41.44, \mathrm{O} 20.29, \mathrm{Fe} 0.21, \mathrm{Na} 0.10$ and $\mathrm{Cl} 0.10$. The sealing agent on the cold sprayed Al coating surface produced some volatilization under the high-temperature remelting condition; the $\mathrm{Al}$ atom-rich zones existed on the worn track, as shown in Figure $6 \mathrm{c}$. The $\mathrm{C}$ and $\mathrm{O}$ were uniformly distributed, indicating that $\mathrm{C}$ and $\mathrm{O}$ appeared as the form of compounds on the Al coating, which were the remains of sealing agents, as shown in Figure 6d,e. The $\mathrm{C}$ and $\mathrm{O}$ appeared as atom-poor zones on the worn track: this was because the remains of sealing agent were peeled off from the Al coating. The Fe was massively distributed on the laser remelted Al coating, as shown in Figure $6 \mathrm{f}$, which was caused by the thermal diffusion of Fe in the substrate into the side of Al coating in the LR process. The $\mathrm{Na}$ and $\mathrm{Cl}$ content were very little, which were the residues came from $\mathrm{NaCl}$ solution, as shown in Figure $6 \mathrm{~g}$, $\mathrm{h}$.

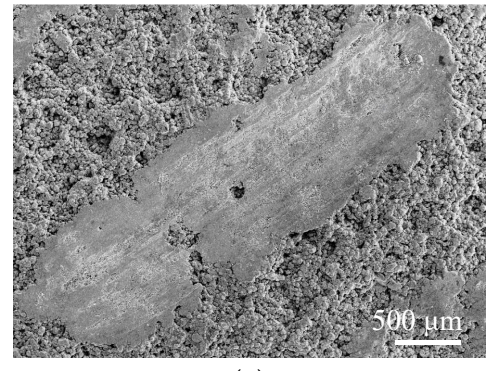

(a)

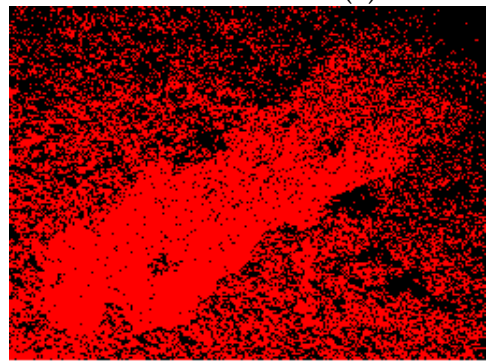

(c)

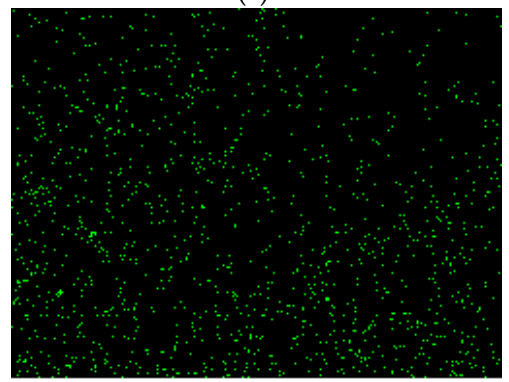

(f)

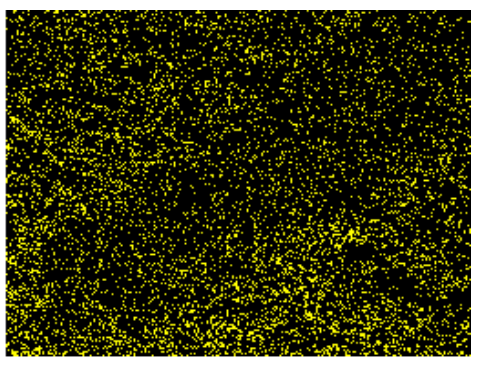

(d)

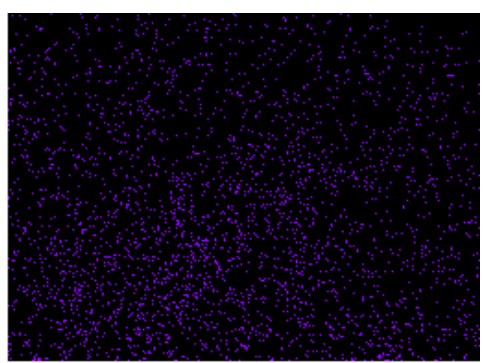

(g)

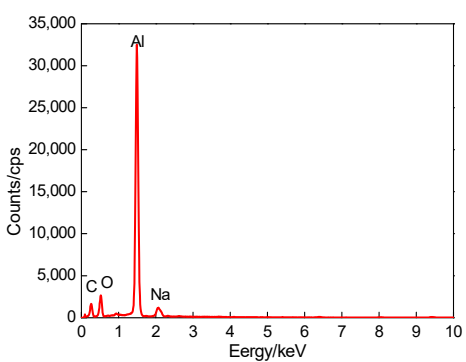

(b)

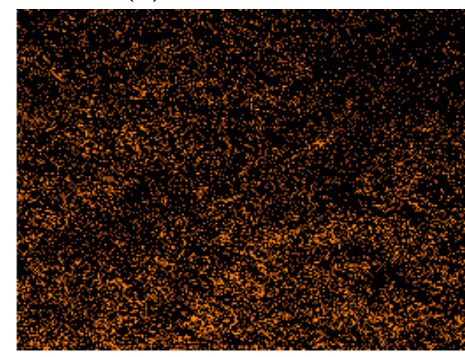

(e)

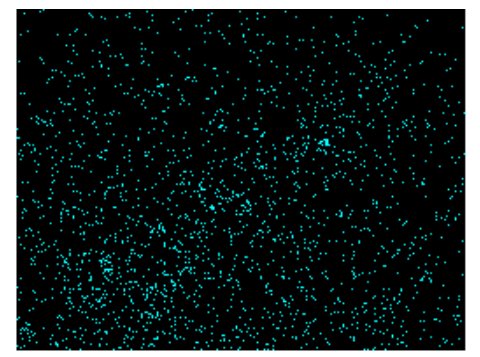

(h)

Figure 6. Plane scan analysis of worn track at wear speed of 300 times/min (wear load of $1 \mathrm{~N}$ ). (a) Plane scanned position; (b) Result of plane scan analysis; (c) Al content; (d) C content; (e) O content; (f) Fe content; (g) Na content; (h) Cl content. 
Figure 7a shows the plane scanned position of worn track at the wear speed of $400 \mathrm{times} / \mathrm{min}$. The plane scanned result is shown in Figure $7 \mathrm{~b}$, the mass fractions of chemical elements (mass, \%): $\mathrm{Al}$ 52.74, C 20.59, O 25.48, Fe 0.39, $\mathrm{Na} 0.27$ and $\mathrm{Cl}$ 0.53, and the corresponding atomic fractions (at, \%): $\mathrm{Al} 37.02, \mathrm{C} 32.71, \mathrm{O} 29.72, \mathrm{Fe} 0.13, \mathrm{Na} 0.22$ and $\mathrm{Cl}$ 0.2. The $\mathrm{Al}$ content increased by $18 \%$ than that at the wear speed of 300 times/min, as shown in Figure 7c. The other elements changed little, the plane scan distribution was the same as that at the wear speed of 300 times/min, as shown in Figure $7 \mathrm{~d}-\mathrm{g}$.

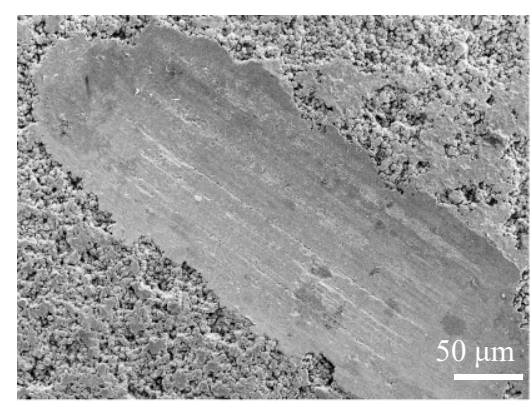

(a)

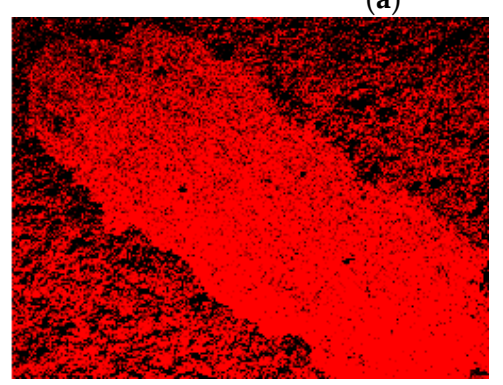

(c)

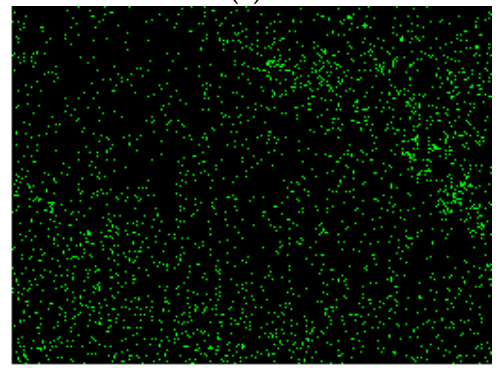

(f)

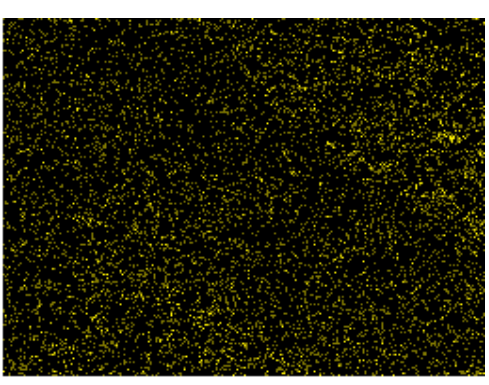

(d)

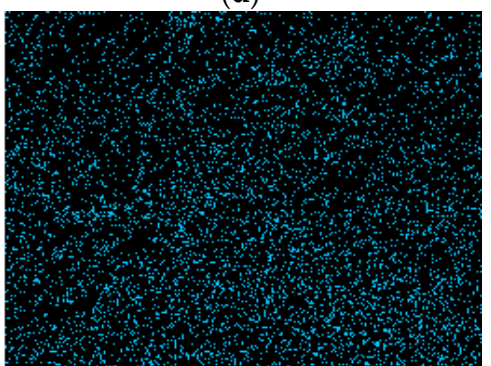

(g)

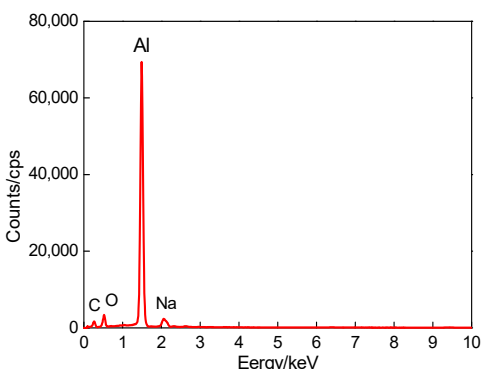

(b)

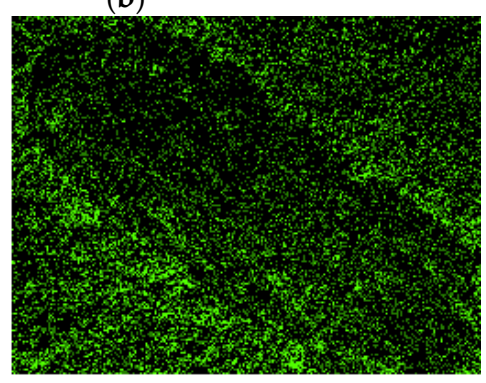

(e)

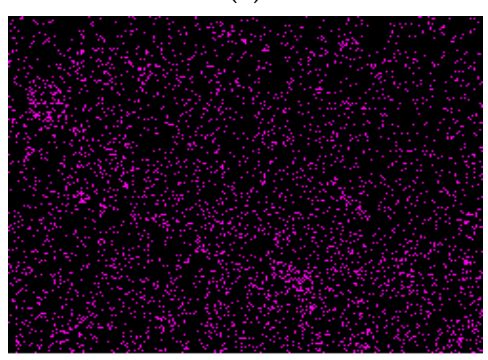

(h)

Figure 7. Plane scan analysis of worn track at wear speed of 400 times/min (wear load of $1 \mathrm{~N}$ ). (a) Plane scanned position; (b) Result of plane scan analysis; (c) Al content; (d) C content; (e) O content;

(f) Fe content; (g) Na content; (h) $\mathrm{Cl}$ content.

Figure $8 \mathrm{a}$ shows the plane scanned position of a worn track at the wear speed of $500 \mathrm{times} / \mathrm{min}$. The plane scanned result is shown in Figure $8 \mathrm{~b}$, the mass fractions of chemical elements (mass, \%) were $\mathrm{Al} 55.22, \mathrm{C} 22.49, \mathrm{O} 20.95, \mathrm{Fe} 0.79, \mathrm{Na} 0.21$ and $\mathrm{Cl} \mathrm{0.34}$, and the corresponding atomic fractions (at, \%) were $\mathrm{Al} 38.88, \mathrm{C} 35.51, \mathrm{O} 24.99$, Fe $0.27, \mathrm{Na} 0.17$ and $\mathrm{Cl} 0.18$. The $\mathrm{Al}$ increased by 5\% compared to that at the wear speed of 400 times/min, as shown in Figure 8c. The other elements changed little: their plane scanning distributions were the same as those at the wear speeds of 300 and 400 times $/ \mathrm{min}$, as shown in Figure $8 \mathrm{~d}-\mathrm{g}$.

From the above analyses, the Al content on the worn tracks increased as the wear speeds increased, this was because the increasing of wear speeds resulted in increasing the abrasive wear to widen the widths of worn tracks, and the Al content increased correspondingly. 


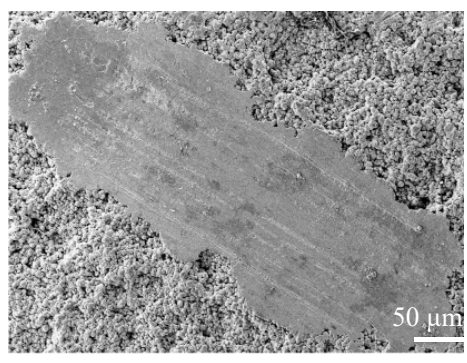

(a)

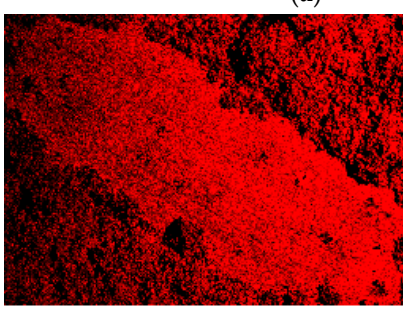

(c)

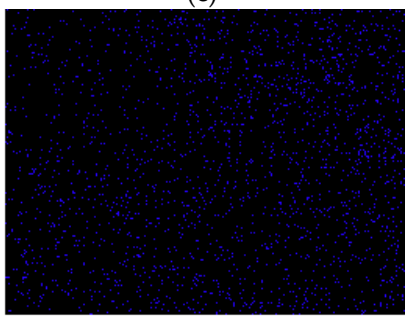

(f)

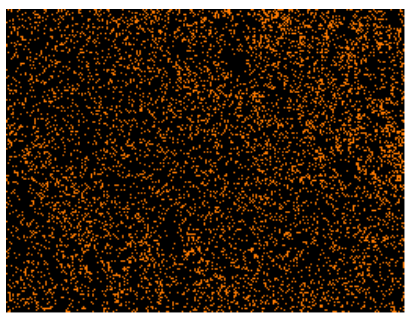

(d)

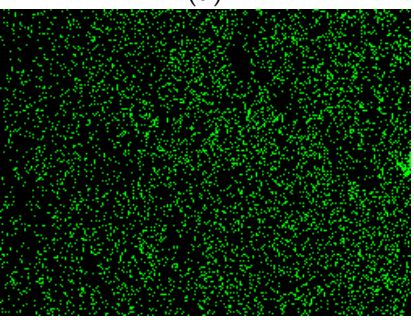

(g)

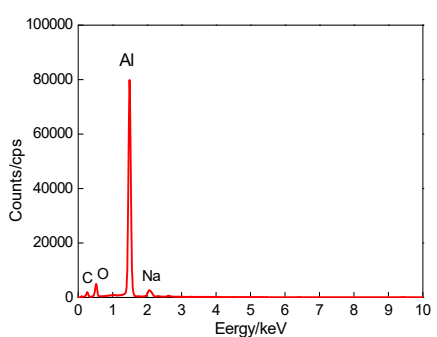

(b)

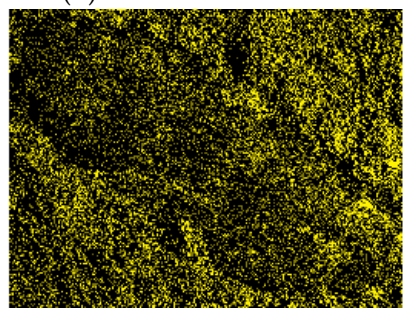

(e)

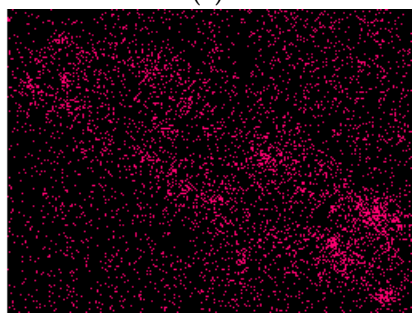

(h)

Figure 8. Plane scan analysis of worn track at wear speed of 500 times $/$ min (wear load of $1 \mathrm{~N}$ ). (a) Plane scanned position; (b) Result of plane scan analysis; (c) Al content; (d) C content; (e) O content; (f) Fe content; (g) Na content; (h) Cl content.

\subsection{Wear Mechanism}

A large number of corrosion pits appeared on the worn track at the wear load of $0.5 \mathrm{~N}$, and rough and loose corrosion products were formed on the $\mathrm{Al}$ coating surface, as shown in Figure 9a. The friction pairs were contacted on the $\mathrm{Al}$ coating surface, and the characteristics of cold spraying resulted in the loose and porosity on the $\mathrm{Al}$ coating surface at the low wear loads. The $\mathrm{Cl}^{-}$in $3.5 \% \mathrm{NaCl}$ solution entered the $\mathrm{Al}$ coating internally through the porosity and corrosion, which caused the $\mathrm{Al}$ on the $\mathrm{Al}$ coating surface to become a soluble salt. Because of the high conductivity of $\mathrm{Cl}^{-}$, the cation transfer speed was improved, which accelerated the corrosion current flow and decreased the corrosion rate.

The corrosion mechanism of $\mathrm{Al}$ coating was primarily electrochemical corrosion. The electrode reactions are shown as follows.

On the anode, the reaction was

$$
\mathrm{Al} \rightarrow \mathrm{Al}^{3+}+3 \mathrm{e}^{-}
$$

On the cathode, the reaction was

$$
\begin{gathered}
\mathrm{O}_{2}+\mathrm{H}_{2} \mathrm{O}+4 \mathrm{e}^{-} \rightarrow 4 \mathrm{OH}^{-} \\
\mathrm{Al}^{3+}+3 \mathrm{OH}^{-} \rightarrow \mathrm{Al}_{2}(\mathrm{OH})_{3} \\
2 \mathrm{Al}_{2}(\mathrm{OH})_{3} \rightarrow \mathrm{Al}_{2} \mathrm{O}_{3}+3 \mathrm{H}_{2} \mathrm{O} \\
\mathrm{Al}_{2}(\mathrm{OH})_{3}+\mathrm{Cl}^{-} \rightarrow \mathrm{Al}(\mathrm{OH})_{2} \mathrm{Cl}+\mathrm{OH}^{-} \\
\mathrm{Al}(\mathrm{OH})_{2} \mathrm{Cl}^{-}+\mathrm{Cl}^{-} \rightarrow \mathrm{Al}(\mathrm{OH}) \mathrm{Cl}_{2}+\mathrm{OH}^{-} \\
\mathrm{Al}(\mathrm{OH}) \mathrm{Cl}_{2}+\mathrm{Cl}^{-} \rightarrow \mathrm{AlCl}_{3}+\mathrm{OH}^{-}
\end{gathered}
$$


During the corrosion reaction, the $\mathrm{Al}^{3+}$ concentration in Equation (2) increased, which reacted with the $\mathrm{OH}^{-}$in Equation (3) and produced the white precipitate of $\mathrm{Al}(\mathrm{OH})_{3}$ in Equation (4) after corrosion reaction. The precipitate underwent a secondary reaction to produce the $\mathrm{Al}_{2} \mathrm{O}_{3}$ in Equation (5) [30]. The rest of the $\mathrm{Al}_{2}(\mathrm{OH})_{3}$ reacted with the $\mathrm{Cl}^{-}$to produce the $\mathrm{Al}(\mathrm{OH})_{2} \mathrm{Cl}$ in Equation (6), showing an obvious corrosion of the $\mathrm{Al}$ coating. The $\mathrm{Cl}^{-}$adhered to the $\mathrm{Al}(\mathrm{OH})_{2} \mathrm{Cl}^{-}$on the $\mathrm{Al}$ coating to produce the $\mathrm{Al}(\mathrm{OH}) \mathrm{Cl}_{2}$ in Equation (7), resulting in a thinner oxidation film and a bared $\mathrm{Al}$ coating. The $\mathrm{Al}(\mathrm{OH}) \mathrm{Cl}_{2}$ continuously reacted with the $\mathrm{Cl}^{-}$to produce the $\mathrm{AlCl}_{3}$ in Equation (8) [31].

The hardness of the friction pair increased at the wear load of $1.0 \mathrm{~N}$, while the porosity rate and corrosion degree decreased, as shown in Figure 9b; only a small number of isolated corrosion pits existed on the corrosion area. It can be seen that the wear mechanism was corrosion wear at the wear loads of 0.5 and $1.0 \mathrm{~N}$. There were strip-worn tracks and small scaly flakes on the worn tracks at the wear load of $1.5 \mathrm{~N}$, as shown in Figure 9c. The new abrasive particles were always produced in the wear process, and ground the $\mathrm{Al}$ coating to form the striped furrows on the $\mathrm{Al}$ coating surface, causing the $\mathrm{Al}$ particles on the $\mathrm{Al}$ coating surface to fall off; the wear mechanism was abrasive wear [32]. Due to the stress concentration at the contact point between the $\mathrm{Al}$ coating surface and the ceramic ball, the fatigue cracks and worn debris appeared under the action of circular stress, and such cracks mainly appeared in the form of scaly flakes, at the same time, the hardness of worn track increased, resulting in fatigue wear [33-35]. There were flaky debris appearing on the worn track, and the hardness on the worn track was $71.10 \mathrm{HV}$, larger than the $\mathrm{Al}$ coating surface, which was the specific feature of fatigue wear. The wear mechanism of cold sprayed $\mathrm{Al}$ coating at the load of $1.5 \mathrm{~N}$ was abrasive wear + fatigue wear.

The cold-sprayed Al coating surface was denser after LR, and the porosity and defects reduced, which prevented the adsorption and internal diffusion of $\mathrm{Cl}^{-}$and slowed down the corrosion rate. The hardness of worn tracks at the loads of $0.5,1.0$ and $1.5 \mathrm{~N}$ was $152.12,163.27$, and $168.42 \mathrm{HV}$, respectively, which was much higher than that of Al coating surface. As shown in Figure 10a-c, no corrosion pits and corrosion products were found, but the scaly worn debris appeared on the worn tracks, which were corresponded to the characteristics of fatigue wear. The stripe track appeared caused by abrasive wear on the worn track, which was concluded that the Al coating undergone the abrasive wear. The wear mechanism of laser remelted $\mathrm{Al}$ coating at the loads of $0.5,1.0$ and $1.5 \mathrm{~N}$ was abrasive wear + fatigue wear.

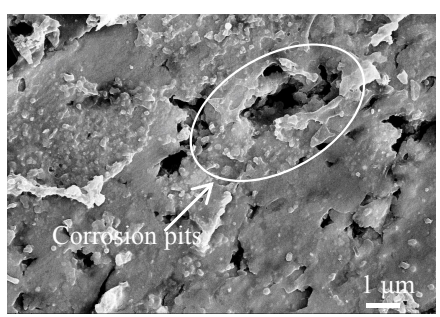

(a)

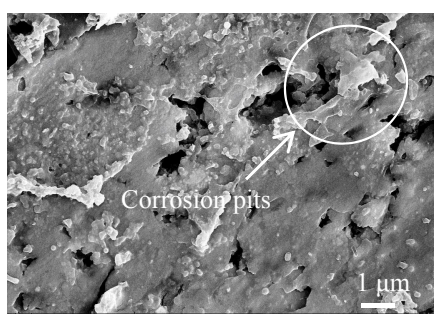

(b)

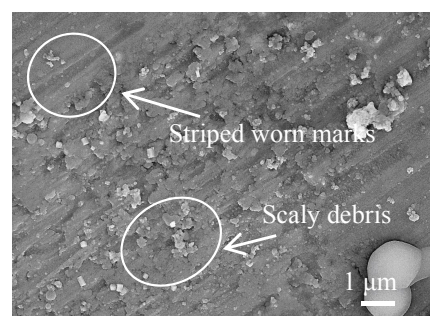

(c)

Figure 9. Morphologies of worn track on cold sprayed Al coatings before LR. (a) Wear load of $0.5 \mathrm{~N}$; (b) Wear load of $1.0 \mathrm{~N}$; (c) Wear load of $1.5 \mathrm{~N}$.

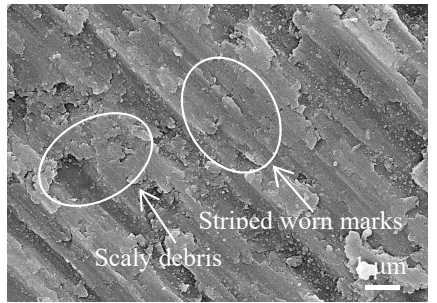

(a)

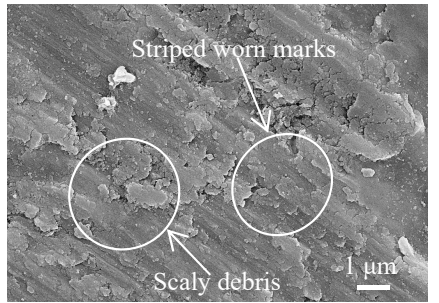

(b)

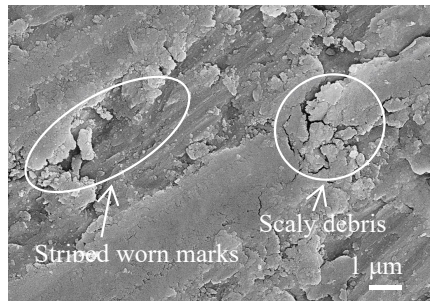

(c)

Figure 10. Morphologies of worn track on cold sprayed Al coatings after LR. (a) Wear load of $0.5 \mathrm{~N}$; (b) Wear load of $1.0 \mathrm{~N}$; (c) Wear load of $1.5 \mathrm{~N}$. 


\section{Conclusions}

(1) The average hardness of cold sprayed Al coating was $49.96 \mathrm{HV}$, while that after LR was $104.66 \mathrm{HV}$, increasing by $109.5 \%$ compared to that before LR.

(2) The average COFs of cold sprayed Al coatings at the wear loads of 1,3 and $5 \mathrm{~N}$ were $0.285,0.239$, and 0.435 , respectively, and the corresponding wear rates were $1.60 \times 10^{-4}$, $2.36 \times 10^{-4}$ and $2.40 \times 10^{-4} \mathrm{~mm}^{3} / \mathrm{m} \cdot \mathrm{N}$, respectively; while those after LR were $0.243,0.227$, and 0.327, respectively, and the corresponding wear rates are $1.59 \times 10^{-4}, 1.70 \times 10^{-4}$ and $1.94 \times 10^{-4} \mathrm{~mm}^{3} / \mathrm{m} \cdot \mathrm{N}$, respectively, showing that the friction-wear properties of $\mathrm{Al}$ coatings are improved after LR.

(3) The average COFs of $\mathrm{Al}$ coatings at the wear speeds of 300, 400 and 500 times/min (wear load of $1.0 \mathrm{~N}$ ) were $0.294,0.279$, and 0.239 , respectively, and the corresponding wear rates were $1.06 \times 10^{-4}, 1.24 \times 10^{-4}$, and $1.70 \times 10^{-4} \mathrm{~mm}^{3} / \mathrm{m} \cdot \mathrm{N}$, showing the lower COFs and wear rates.

(4) The wear mechanism of cold sprayed $\mathrm{Al}$ coating in $3.5 \% \mathrm{NaCl}$ solution is corrosion wear under 0.5 and $1.0 \mathrm{~N}$ load, which is abrasive wear + fatigue wear under $1.5 \mathrm{~N}$; while that after LR that is abrasive wear + fatigue wear, with no corrosion wear, showing that LR reduces the porosity of $\mathrm{Al}$ coating and improve its corrosion wear resistance.

Acknowledgments: Financial support for this research by the Key Research and Development Project of Jiangsu Province (BE2016052) and the Research Project of Scientific Practice Innovation for Graduate Students of Jiangsu Province (SJCX17_0714) are gratefully acknowledged.

Author Contributions: Zhang Jing and Kong Dejun conceived and designed the experiments; Zhang Jing performed the experiments; Zhang Jing analyzed the data; Zhang Jing and Kong Dejun wrote the paper.

Conflicts of Interest: The authors declare no conflict of interest.

\section{References}

1. Ribeiro, J.; Santiago, A.; Rigueiro, C. Damage model calibration and application for S355 steel. Procedia Struct. Integr. 2016, 2, 656-663. [CrossRef]

2. Gao, W.; Wang, D.; Cheng, F.; Di, X.; Deng, C. Microstructural and mechanical performance of underwater wet welded S355 steel. J. Mater. Process. Technol. 2016, 238, 333-340. [CrossRef]

3. Zhong, L.; Wang, Z.Y.; Zhang, H.D. Research progress of precipitation mechanism and apparatus of cold spray. Surf. Technol. 2015, 44, 15-22.

4. Dykhuizen, R.C.; Smith, M.F.; Gilmore, D.L.; Neiser, R.A.; Jiang, X. Impact of high velocity cold spray particles. J. Therm. Spray Technol. 1999, 8, 559-564. [CrossRef]

5. Steenkiste, T.H.V.; Smith, J.R.; Teets, R.E. Aluminum coatings via kinetic spray with relatively large powder particles. Surf. Coat. Technol. 2002, 1154, 237-252. [CrossRef]

6. Assadi, H.; Gärtner, F.; Stoltenhoff, T.; Kreye, H. Bonding mechanism in cold gas spraying. Acta Mater. 2003, 51, 4379-4394. [CrossRef]

7. Schmidt, T.; Gärtner, F.; Assadi, H.; Kreye, H. Development of a generalized parameter window for cold spray deposition. Acta Mater. 2006, 54, 729-742. [CrossRef]

8. Gärtner, F.; Schmidt, T.; Stoltenhoff, T.; Kreye, H. Recent developments and potential applications of cold spraying. Adv. Eng. Mater. 2010, 8, 611-618. [CrossRef]

9. Spencer, K.; Luzin, V.; Matthews, N.; Zhang, M.X. Residual stresses in cold spray Al coatings: The effect of alloying and of process parameters. Surf. Coat. Technol. 2012, 206, 4249-4255. [CrossRef]

10. Chen, D.; Li, Z.S.; Wu, H.L.; Cong, D.L. Study on corrosion resistance of cold sprayed pure aluminum coating. Surf. Technol. 2016, 45, 174-179.

11. Qian, M.; Li, D.; Liu, S.B.; Gong, S.L. Corrosion performance of laser-remelted Al-Si coating on magnesium alloy AZ91D. Corros. Sci. 2010, 52, 3554-3560. [CrossRef]

12. Wang, Y.; Li, C.; Guo, L.; Tian, W. Laser remelting of plasma sprayed nanostructured $\mathrm{Al}_{2} \mathrm{O}_{3}-\mathrm{TiO}_{2}$, coatings at different laser power. Surf. Coat. Technol. 2010, 204, 3559-3566. [CrossRef] 
13. Poza, P.; Múnez, C.J.; Garrido-Maneiro, M.A.; Vezzù, S.; Rech, S. Mechanical properties of Inconel 625 coldsprayed coatings after laser remelting. Depth sensing indentation analysis. Surf. Coat. Technol. 2014, 243, 1-57. [CrossRef]

14. Wang, L.; Wang, N.; Yao, W.J.; Zheng, Y.P. Effect of substrate orientation on the columnar-to-equiaxed transition in laser surface remelted single crystal superalloys. Acta Mater. 2015, 88, 283-292. [CrossRef]

15. Wang, Y.; Li, C.G.; Tian, W.; Yang, Y. Laser surface remelting of plasma sprayed nanostructured $\mathrm{Al}_{2} \mathrm{O}_{3}-13$ wt $\% \mathrm{TiO}_{2}$ coatings on titanium alloy. Appl. Surf. Sci. 2009, 255, 8603-8610. [CrossRef]

16. Riveiro, A.; Mejías, A.; Lusquiños, F.; Val, J.D.; Comesaña, R.; Pardo, J.; Pou, J. Optimization of laser cladding for Al coating production. Phys. Procedia 2013, 41, 327-334. [CrossRef]

17. Yao, J.; Yang, L.; Li, B.; Li, Z. Beneficial effects of laser irradiation on the deposition process of diamond/Ni60 composite coating with cold spray. Appl. Surf. Sci. 2015, 330, 300-308. [CrossRef]

18. Almangour, B.; Grzesiak, D.; Yang, J.M. Scanning strategies for texture and anisotropy tailoring during selective laser melting of TiC/316L stainless steel nanocomposites. J. Alloys Compd. 2017, 728, 424-435. [CrossRef]

19. Almangour, B.; Grzesiak, D.; Jenn-MingYang. Selective laser melting of TiC reinforced 316L stainless steel matrix nanocomposites: Influence of starting TiC particle size and volume content. Mater. Des. 2016, 104, 141-151. [CrossRef]

20. Sun, Z.; Zhang, D.H.; Yan, B.X.; Kong, D.J. Effects of laser remelting on microstructures and immersion corrosion performance of arc sprayed $\mathrm{Al}$ coating in 3.5\% NaCl solution. Opt. Laser Technol. 2018, 99, 282-290. [CrossRef]

21. Li, B.; Jin, Y.; Yao, J.; Zhang, Q. Influence of laser irradiation on deposition characteristics of cold sprayed Stellite-6 coatings. Opt. Laser Technol. 2018, 100, 27-39. [CrossRef]

22. Kang, N.; Verdy, C.; Coddet, P.; Xie, Y.C.; Fu, Y.Q.; Liao, H.L.; Coddet, C. Effects of laser remelting process on the microstructure, roughness and microhardness of in-situ cold sprayed hypoeutectic Al-Si coating. Surf. Coat. Technol. 2017, 318, 355-359. [CrossRef]

23. Podrabinnik, P.; Grigoriev, S.; Shishkovsky, I. Laser post annealing of cold-sprayed Al/alumina-Ni composite coatings. Surf. Coat. Technol. 2015, 271, 265-268. [CrossRef]

24. Srinivasa, R.B.; Wang, D.; Price, T.; Zhang, D.; Keshri, A.K.; Chen, Y.; McCartney, D.G.; Shipway, P.H.; Agarwal, A. Microstructure and wear properties of aluminum/aluminum-silicon composite coatings prepared by cold spraying. Surf. Coat. Technol. 2009, 204, 503-510.

25. Anandkumar, R.; Almeida, A.; Vilar, R. Microstructure and sliding wear resistance of an Al-12 wt \% Si/TiC laser clad coating. Wear 2012, 282-283, 31-39. [CrossRef]

26. Pitchuk, S.B.; Boesl, B.; Zhang, C.; Lahiri, D.; Nieto, A.; Sundararajan, G.; Agarwal, A. Dry sliding wear behavior of cold sprayed aluminum amorphous/nanocrystalline alloy coatings. Surf. Coat. Technol. 2014, 238, 118-125. [CrossRef]

27. Shockley, J.M.; Descartes, S.; Vo, P.; Irissou, E.; Chromik, R.R. The influence of $\mathrm{Al}_{2} \mathrm{O}_{3}$ particle morphology on the coating formation and dry sliding wear behavior of cold sprayed $\mathrm{Al}-\mathrm{Al}_{2} \mathrm{O}_{3}$ composites. Surf. Coat. Technol. 2015, 270, 324-333. [CrossRef]

28. Gao, M.H.; Lu, W.Y.; Yang, B.J.; Zhang, S.D.; Wang, J.Q. High corrosion and wear resistance of Al-based amorphous metallic coating synthesized by HVAF spraying. J. Alloys Compd. 2018, 735, 1363-1373. [CrossRef]

29. Ramesh, C.S.; Ahamed, A. Friction and wear behaviour of cast Al 6063 based in situ metal matrix composites. Wear 2011, 271, 1928-1939. [CrossRef]

30. Bai, X.M.; Tang, J.Q.; Gong, J.M.; Lü, X.L. Corrosion performance of $\mathrm{Al}-\mathrm{Al}_{2} \mathrm{O}_{3}$ cold sprayed coatings on mild carbon steel pipe under thermal insulation. Chin. J. Chem. Eng. 2017, 25, 533-539. [CrossRef]

31. Nejadseyfi, O.; Shokuhfar, A.; Dabiri, A.; Azimi, A. Combining equal-channel angular pressing and heat treatment to obtain enhanced corrosion resistance in 6061 aluminum alloy. J. Alloys Compd. 2015, 648, 912-918. [CrossRef]

32. Allachi, H.; Chaouket, F.; Draoui, K. Protection against corrosion in marine environments of AA6060 aluminium alloy by cerium chlorides. J. Alloys Compd. 2010, 491, 223-229. [CrossRef]

33. Khruschov, M.M. Principles of abrasive wear. Wear 1974, 28, 69-88. [CrossRef] 
34. Wu, G.; Dai, W.; Zheng, H.; Wang, A. Improving wear resistance and corrosion resistance of AZ31 magnesium alloy by DLC/AlN/Al coating. Surf. Coat. Technol. 2010, 205, 2067-2073. [CrossRef]

35. Yonekura, D.; Fujita, J.; Miki, K. Fatigue and wear properties of Ti-6Al-4V alloy with Cr/CrN multilayer coating. Surf. Coat. Technol. 2015, 275, 232-238. [CrossRef]

(c) 2018 by the authors. Licensee MDPI, Basel, Switzerland. This article is an open access article distributed under the terms and conditions of the Creative Commons Attribution (CC BY) license (http:/ / creativecommons.org/licenses/by/4.0/). 